\title{
News from P.R.China
}

\section{New Patent Agency Service Standard will Be implemented}

The State Intellectual Property Office (SIPO), All-China Patent Agents Association, the Intellectual Property Office of Jiangsu Province and the Intellectual Property Research Center of Jiangsu Province jointly drafted the national standard, Patent Agency Service Standard (Standard No. GBT34833-2017). The compiling work of Patent Agency Service Standard (draft version for soliciting opinions) was finished in February 2016. The draft was issued to the public to solicit opinions and suggestions for revision. After nearly two years of revision, the standard was released recently and will be implemented on January 1, 2018.

The Patent Agency Service Standard was formulated in strict accordance with the principles of standardization, mainly including scope, general provisions, management requirements and so on. The purpose of this standard is to standardize the service process of patent agency, realize the process management of patent agency service, improve the quality of patent agency service, and promote the patent agency to serve the construction of intellectual property powerful country better.

The Patent Agency Service Standard proposes requirements of agency management, business management, service quality, evaluation and improvement from the point of view of service quality management standardization around the core goal of improving the quality of patent agency service. It will focus on solving the prominent problems in the process of patent agency service, such as patent agency management, patent agency service procedure, patent agency service quality and so on. The compiling team of Patent Agency Service Standard considered the demand of different patent agencies on scales and types. The team extracted the common characteristics and standardized the service behavior to make the standard contents reasonable and expand the application of standard.

http://www.sipo.gov.cn/zscqgz/2017/201711/t20171115_ 1320182.html html

http://www.sipo.gov.cn/tz/gz/201602/t20160204_1237326.

Ying-Qi Xu

Chengdu Documentation and Information Center, Chinese Academy of Sciences.

\section{China and Brazil launch pilot patent prosecution highway}

The leaders of State Intellectual Property Office of P. R. China (SIPO) and Brazilian National Institution of Intellectual Property (INPI) had a meeting on November 13, 2017. On the meeting, a more profound bilateral cooperation was discussed. A memorandum of understanding (MoU) and an agreement on a joint patent prosecution highway (PPH) were subscribed.

The new MoU highlighted the latest features and demands of IP cooperation between China and Brazil. It will promote development of IP systems in the two countries, providing more efficient services to patent applicants and assignees from both countries. It also elevates IPR protection and public awareness, building up better IP environment.

SIPO and INPI will launch PPH pilot program on February 1, 2018. It will facilitate the applicants from the two countries to have their patent applications examined in an expedited manner in the other office. The PPH pilot program meets common interests, catering the needs for the healthy development in the economy and trade between China and Brazil. It also promotes IP creation and IPR protection of the two countries. It will be a model of IP cooperation among BRICS countries.

http://www.sipo.gov.cn/zscqgz/2017/201711/t20171115_ 1320160.html

Ying-Qi Xu

Chengdu Documentation and Information Center, Chinese Academy of Sciences.

\section{Reference Table for International Design Classification and National Economy Industries Classification (trial) published}

Recently, the State Intellectual Property Office (SIPO) published Reference Table for International Design Classification and National Economy Industries Classification (trial) (hereinafter referred to as the Reference Table).

The Reference Table establishes mapping relationship between design patents and national economy industries to provide a direct reference for industrial classification of design patent, which benefits the statistical analysis of science data and economic data from an industrial perspective.

The Reference Table complies with the principle of minimum classification, product comparison and comprehensive comparison, and compares the international design classification to the corresponding small, medium or large categories in the national economy industries. The national economy, which has a mapping relationship with the international design classification, has a total of 243 sub-categories, 22 middle-level categories and 1 large-scale category, all concentrated in the manufacturing sector.

The reference table, formulated by SIPO, is a significant and fundamental project to strengthen the related evaluation of patent activities and economic benefits proposed in the Protection and Application of Intellectual Property Rights during the 13th Fiveyear Plan. So far, China has initially established a patent classification system covering international patent classification and international design classification as well as a reference system of national economy industries.

http://www.sipo.gov.cn/zscqgz/2017/201711/t20171103_ 1319929.html

http://www.sipo.gov.cn/tz/201711/P020171101567681940817. 
pdf

Ji-Qiang Shi

Chengdu Documentation and Information Center, Chinese Academy of Sciences.

\section{China has become the second largest target market for patent portfolio}

Recently, a special project of the State Intellectual Property Office (SIPO) entitled "Research on Global Technological Innovation Based on Patented Information" has released Global Patent Innovation Research [Report2016], which reveals that China has become the target market for patent portfolio only second to the United States. Japan and the U.S. attach great importance to the Chinese market, owning one fifth (combined) of all invention patents granted in China.

The report summarizes the global patent innovation from 2008 to 2015 and makes a comparative study and analysis on the technological innovation of major tech-heavy countries in the world. The report notes that from 2008 to 2015, Chinese invention patents published and granted boasted annual growth rates of $20.97 \%$ and $22.48 \%$ respectively. Technological innovation in China contributes global patented technology innovation.

According to the report, from 2012 to 2015, China ranked the first in invention patents granted in 13 technological fields including measurement and organic fine chemistry out of all 35 fields classified by the World Intellectual Property Organization
(WIPO).

The report finds that China still faces challenges in patented technology innovation though having become the second largest target market for patent portfolio. Problems such as discordance of patent quantity and quality, imbalanced development among regions require to be addressed. The report puts forward suggestions to solve these problems. Firstly, adhere to policy support and strategy guidance in order to improve the quality of technological innovation; secondly, encourage various regions across the country to conduct technological innovation and patent portfolio based on their regional advantages; thirdly, advocate in-depth exchange and cooperation between industrial and academic fields, promoting combination of production, teaching and research with respect to patents; fourthly, optimize the work on patent information, giving strong support for patented technology innovation.

Since its debut in 2014, the report has provided important reference for following and understanding patent-related innovative activities in major countries in particular in China.

http://www.sipo.gov.cn/zscqgz/2017/201709/t20170915_ 1318626.html

Ji-Qiang Shi

Chengdu Documentation and Information Center, Chinese Academy of Sciences. 